\title{
CORPO, GÊNERO, SEXUALIDADE, RAÇA E ETNIA NOS CURSOS DE LICENCIATURA DA UNIVERSIDADE FEDERAL DO PAMPA
}

\section{BODY, GENDER, SEXUALITY, RACE AND ETHNIC ON UNIVERSIDADE FEDERAL DO PAMPA'S TEACHING DEGREES}

\author{
DAMACENA, Carla Adriane Marcelino \\ karlars223@gmail.com \\ FAEL - Faculdade Fael \\ SOARES, Emerson de Lima Soares \\ emersonsoareslima@hotmail.com \\ UFSM - Universidade Federal de Santa Maria \\ SILVA, Fabiane Ferreira da \\ fabianesilva@unipampa.edu.br \\ UNIPAMPA - Universidade Federal do Pampa
}

RESUMO Os/as professores/as convivem diariamente com situações de preconceito, racismo, homofobia, sexismo, entre outras, e muitas vezes acabam por reforçar essas situações. É fundamental a discussão das questões de corpo, gênero, sexualidade, raça e etnia nos cursos de licenciatura. Este trabalho buscou investigar essas questões nos Projetos Pedagógicos dos Cursos de Licenciatura da Universidade Federal do Pampa. Verificamos que os cursos de Ciências da Natureza e Educação Física de Uruguaiana, Ciências da Natureza de Dom Pedrito e História de Jaguarão apresentam componentes curriculares que tratam essas questões, contribuindo para a formação inicial de professores/as aptos/as para abordarem essas temáticas, bem como para (re) pensarem as práticas existentes na escola.

Palavras-Chave: Corpo. Formação Docente. Gênero. Raça e Etnia. Sexualidade.

\begin{abstract}
Teachers live daily with situations of prejudice, racism, homophobia, sexism, among others, and often end up reinforcing these situations. It is essential discussing body, gender, sexuality, race and ethnicity issues in teaching training majors. This study aimed to investigate these issues in the Pedagogical Projects of the Federal University of Pampa's undergraduate programs. We confirmed that the majors of Natural Sciences and Physical Education in Uruguaiana city, Natural Sciences in Dom Pedrito and History in Jaguarão present courses that address these issues, contributing to the initial formation of graduate teachers able to address these issues and to (re)think existing practices at school.
\end{abstract}

Keywords: Body. Teaching Training. Gender. Race and Ethnicity. Sexuality.

\section{INTRODUÇÃO}




\section{Atos de Pesquisa em Educação - ISSN 1809-0354 \\ Blumenau, v. 12, n.3, p.783-806, set./dez. 2017 \\ DOI: http://dx.doi.org/10.7867/1809-0354.2017v12n3p783-806}

O anseio em construir uma sociedade justa em que as diferenças sejam respeitadas tem sido um grande desafio para a educação. A escola não ensina apenas conteúdos conceituais, mas tem sido um dos locais importantes na (re) produção de representações sobre as questões de corpo, gênero, sexualidade, raça e etnia.

Os/As profissionais da educação convivem diariamente com situações de preconceito, racismo, homofobia, sexismo, entre outras, e muitas vezes acabam por reforçar essas situações, pois discutir essas temáticas requer estudo e preparo. Desse modo, é fundamental a inserção das discussões sobre corpo, gênero, sexualidade, raça e etnia nos currículos dos cursos de formação de professores/as, pois estes/as estarão futuramente participando ativamente da constituição dos sujeitos de nossa sociedade.

Cabe destacar que a formação inicial que atenda às temáticas que estamos defendendo neste texto está prevista legalmente no âmbito nacional, a exemplo da RESOLUÇÃO N 2, DE $1^{\circ}$ DE JULHO DE 2015 que define as Diretrizes Curriculares Nacionais para a formação inicial em nível superior (cursos de licenciatura, cursos de formação pedagógica para graduados/as e cursos de segunda licenciatura) e para a formação continuada, a qual destaca no segundo parágrafo do Art. 14. que

\footnotetext{
$\S 2^{\circ}$ Os cursos de formação deverão garantir nos currículos conteúdos específicos da respectiva área de conhecimento ou interdisciplinares, seus fundamentos e metodologias, bem como conteúdos relacionados aos fundamentos da educação, formação na área de políticas públicas e gestão da educação, seus fundamentos e metodologias, direitos humanos, diversidades étnico-racial, de gênero, sexual, religiosa, de faixa geracional, Língua Brasileira de Sinais (Libras), educação especial e direitos educacionais de adolescentes e jovens em cumprimento de medidas socioeducativas. (BRASIL, 2015, p. 12).
}

Vale lembrar também das leis 10.639/03 (BRASIL, 2003) e 11.645/08 (BRASIL, 2008) que estabelecem as diretrizes e bases da educação nacional para inclusão no currículo oficial da rede de ensino a obrigatoriedade da temática "História e Cultura Afro-Brasileira e Indígena", instituindo novas demandas aos/às educadores/as.

Nessa perspectiva, entendemos que os currículos dos cursos de licenciatura não podem se abster de incorporar na formação inicial de professores/as discussões 
Atos de Pesquisa em Educação - ISSN 1809-0354

Blumenau, v. 12, n.3, p.783-806, set./dez. 2017

DOI: http://dx.doi.org/10.7867/1809-0354.2017v12n3p783-806

sobre corpo, gênero, sexualidade, raça e etnia, a fim de formar profissionais preparados/as para trabalhar na perspectiva da diversidade e da garantia dos direitos humanos.

Considerando tais entendimentos, investigamos as questões de corpo, gênero, sexualidade, raça e etnia nos currículos dos cursos de licenciatura da Universidade Federal do Pampa (UNIPAMPA), tomando como material de análise o Projeto Pedagógico de Curso (PPC).

A Universidade Federal do Pampa é uma universidade multicampi ${ }^{1}$, resultante da reivindicação da comunidade regional e foi promovida pelo governo federal brasileiro por meio da política de expansão e renovação das instituições federais de educação superior. A UNIPAMPA surgiu com a responsabilidade de contribuir com a região chamada metade sul do estado do Rio Grande do Sul, que se apresenta como um extenso território, com críticos problemas de desenvolvimento socioeconômico, inclusive de acesso à Educação Básica e à Educação Superior pública.

A Universidade Federal do Pampa possui dezessete cursos de licenciatura espalhados em 08 campi de um total de 10 que a universidade possui que estão localizados nos municípios de Bagé, Caçapava do Sul, Dom Pedrito, Itaqui, Jaguarão, São Borja, São Gabriel e Uruguaiana. Desse modo, analisamos os PPCs dos seguintes cursos de licenciatura: Licenciatura em Física, Licenciatura em Letras - Línguas Adicionais Inglês e Espanhol e Respectivas Literaturas, Letras Português e Literaturas de Língua Portuguesa, Licenciatura em Matemática, em Química e Música do campus Bagé; Licenciatura em Ciências Exatas do campus de Caçapava do Sul; Licenciatura em Ciências da Natureza e em Educação do campo de Dom Pedrito; Licenciatura em Matemática de Itaqui; Licenciatura em História, Letras e Pedagogia de Jaguarão; Licenciatura em Ciências Humanas de São Borja; Licenciatura em Ciências Biológicas de São Gabriel; Licenciatura em Ciências da Natureza e Educação Física de Uruguaiana. Ao olhar para esses documentos, buscamos identificar se contemplam ou não a discussão sobre corpo, gênero, sexualidade, raça e etnia, bem como, a perspectiva teórica adotada.

\footnotetext{
${ }^{1}$ A Universidade Federal do Pampa é considerada multicampi, pois possui unidades de ensino em dez municípios do Rio Grande do Sul, situados na mesorregião Metade Sul do estado.
} 
 \\ Blumenau, v. 12, n.3, p.783-806, set./dez. 2017 \\ DOI: http://dx.doi.org/10.7867/1809-0354.2017v12n3p783-806}

Antes de apresentarmos as análises que tecemos dos PPCs dos cursos de licenciatura da UNIPAMPA, consideramos importante discorrer brevemente acerca de corpo, gênero, sexualidade, raça e etnia, destacando alguns exemplos do contexto escolar, na direção de justificar a importância de uma formação inicial que contemple a discussão apresentada neste texto.

\section{ALGUMAS CONCEPÇÕES ACERCA DO CORPO, GÊNERO, SEXUALIDADE, RAÇA E ETNIA}

Numa aproximação às teorizações mais críticas dos Estudos Feministas e dos Estudos Culturais, na perspectiva pós-estruturalista, compreendemos os sujeitos como tendo múltiplas identidades, que não são fixas, essenciais ou permanentes, por exemplo, sua identidade de gênero, sexual, étnico-racial, geracional, religiosa, de classe, dentre outras.

No contexto dessa discussão, compreendemos o corpo como superfície de inscrição das múltiplas identidades, um híbrido entre biologia e cultura, portanto, o corpo não é apenas materialidade biológica (vale lembrar que essa materialidade também é uma construção social, cultural e histórica). Para Goellner (2003), não são apenas as características biológicas que definem o corpo, mas especialmente os significados construídos no contexto social e cultural. O corpo adquire sentido socialmente. Assim, as inscrições de gênero, sexuais e étnico-raciais no corpo são feitas sempre no âmbito de uma determinada cultura e, logo, com as marcas dessa cultura (LOURO, 2001). O corpo é temporário, mutável e transitório. Ele está continuamente sendo reinventado e alterado de acordo com as inúmeras intervenções e opções presentes em cada cultura.

Entretanto, ainda predomina no currículo vigente na maioria das escolas (ousamos dizer que na universidade também) uma abordagem estritamente biológica sobre o corpo. Para Quadrado (2008, p. 32), o corpo que vem sendo apresentado em sala de aula

[...] é um corpo atemporal, sem história, sem rosto, pés, mãos, sexo, fragmentado em órgãos, funcionalista, descolado do ambiente. Um corpo universal, um corpo que tem um padrão que se repete independentemente de classe, raça, etnia, credo, língua, geração. 


\title{
Atos de Pesquisa em Educação - ISSN 1809-0354 \\ Blumenau, v. 12, n.3, p.783-806, set./dez. 2017 \\ DOI: http://dx.doi.org/10.7867/1809-0354.2017v12n3p783-806
}

Além disso, é importante destacar que o discurso biológico priorizado na escola assenta-se na perspectiva da heteronormatividade, ou seja, na heterossexualidade tomada como norma, regra, padrão de sexualidade. Segundo Foster (2001, p. 19):

\begin{abstract}
A heteronormatividade entende-se a partir da reprodução de práticas e códigos heterossexuais, sustentada pelo casamento monogâmico, amor romântico, fidelidade conjugal, constituição de família (esquema pai-mãefilho(a)(s). Na esteira das implicações da aludida palavra, tem-se a heterossexualidade compulsória, sendo que, por esse último termo, entende-se o imperativo inquestionado e inquestionável por parte de todos os membros da sociedade com o intuito de reforçar ou dar legitimidade às práticas ditas heterossexuais.
\end{abstract}

Nessa perspectiva, a constituição da identidade sexual e de gênero está, desde que se identifica o sexo do bebê, atrelada aos padrões heteronormativos, considerando principalmente o sexo biológico, isto é, a materialidade biológica do corpo. A heteronormatividade impõe limites aos padrões de convivências sociais, ditando regras e modelos a serem seguidos, o que exclui da convivência social outras formas de se relacionar amorosa e sexualmente.

Portanto, discutir as questões de corpo, gênero, sexualidade, raça e etnia são fundamentais, pois um ambiente de convivência diversificada possibilita e colabora para uma educação igualitária, independentemente do gênero, sexualidade, classe, raça e etnia.

As diferenças de gênero são evidentes na educação de meninos e meninas. Geralmente, os meninos são educados de maneira que entendam que podem ser brutos e agir com rigidez, sendo ensinados dessa forma dentro do contexto familiar e social. Por outro lado, a imposição para meninas é que devem ser delicadas, meigas e comportadas. Meninos ainda são educados para serem "pai de família", responsáveis pelo sustento; e as meninas para serem mães, donas de casa e cuidadoras.

Nesse sentido, gênero é definido por Carvalho (2010, p. 76) como:

Gênero é uma dimensão específica da estratificação social e da divisão social do trabalho, relação social, processo de subjetivação e corporificação, papel, norma, ideologia, tecnologia, representação, discurso, imagem/ 


\section{Atos de Pesquisa em Educação - ISSN 1809-0354 \\ Blumenau, v. 12, n.3, p.783-806, set./dez. 2017 \\ DOI: http://dx.doi.org/10.7867/1809-0354.2017v12n3p783-806}

signo, campo de experiência/significação, identidade, modelo de comportamento, estereótipo, performatividade...

Meyer (2003, p. 16), sobre as questões de gênero, diz que:

Gênero aponta para a noção de que, ao longo da vida, através das mais diversas instituições e práticas sociais, nos constituímos como homens e mulheres, num processo que não é linear, progressivo ou harmônico e que também nunca está finalizado ou completo.

Nesse sentido, operar com o conceito de gênero implica operar num viés construcionista, colocando-se contra a naturalização do feminino e do masculino, o que significa dizer que nada é dado a priori, tudo aquilo que se diz sobre masculinidades e feminilidades fez e faz parte de uma construção social, cultural e histórica.

Já a sexualidade se refere às distintas formas do sujeito viver seus desejos e prazeres sexuais, que pode ser com pessoas do mesmo sexo (homossexualidade), do sexo oposto (heterossexualidade), com ambos (bissexualidade) ou sozinho. O/a professor/a deve estar preparado/a para entender que existe uma diversidade de orientações no que diz respeito à sexualidade e que elas não podem ser negadas, ignoradas ou questionadas tomando a heterossexualidade como norma. Para Silva (2011, p. 149):

[...] a sexualidade tem muito mais a ver com a cultura e a história do que com a biologia (embora a biologia também seja uma construção). A sexualidade diz respeito ao modo como as pessoas, social e historicamente, vivem seus desejos e prazeres; às formas pelas quais os sujeitos são incitados a falar sobre ela; às formas pelas quais o sujeito é disciplinado e a sociedade é governada. A sexualidade é o acesso tanto ao corpo quanto à espécie.

Não basta entender biologicamente o indivíduo, é importante entender os aspectos emocionais, socioculturais e históricos, para que assim o/a professor/a inserido/a na escola possa quebrar crenças e preconceitos ligados à sexualidade. Entretanto, segundo Louro (1998, p. 41):

[...] a sexualidade que é geralmente apresentada na escola está em estreita articulação com a família e a reprodução. O casamento constitui a moldura social adequada para seu 'pleno exercício' e os filhos, a consequência ou a 


\title{
Atos de Pesquisa em Educação - ISSN 1809-0354 \\ Blumenau, v. 12, n.3, p.783-806, set./dez. 2017 \\ DOI: http://dx.doi.org/10.7867/1809-0354.2017v12n3p783-806
}

\begin{abstract}
benção desse ato. Dentro desse quadro, as práticas sexuais não reprodutivas ou não são consideradas, deixando de ser observadas, ou são cercadas de receios e medos. A associação da sexualidade ao prazer e ao desejo é deslocada em favor da prevenção dos perigos e das doenças. Nesse contexto que centraliza a reprodução, os/as homossexuais ficam fora da discussão. [...] A homossexualidade é virtualmente negada, mas é, ao mesmo tempo, profundamente vigiada.
\end{abstract}

Assim, a falta de preparo e segurança faz com que a sexualidade seja geralmente atrelada a conceitos puramente biológicos, seguindo conceitos préestabelecidos histórica e culturalmente presentes em nossa sociedade. Além disso, para Britzman (2001), quando os/as professores/as passam conhecimentos sobre sexualidade para os/as alunos/as não permitem que haja questionamento, interrompendo o conhecimento por parte do/a aluno/a sobre o assunto tratado. No contexto dessa discussão, corroboramos a afirmação de Figueiró (2006) quando este nos diz que a abordagem da sexualidade ultrapassa questões biológicas que são trabalhadas na escola. Este tema precisa ser abordado de forma reflexiva, individual e coletiva, permitindo ao/à aluno/a conhecer sua sexualidade, sendo o/a professor/a o/a mediador/a dessa discussão.

É através do corpo que se expressa a sexualidade do indivíduo, portanto disciplinar o corpo é como limitar a sexualidade, e limitá-la é impedir a individualidade do sujeito. Para Foucault (1993, p. 100):

[...] a sexualidade é o nome dado a um dispositivo histórico [...] à grande rede de superfície em que a estimulação dos corpos, a intensificação dos prazeres, a incitação ao discurso, a formação dos conhecimentos, o reforço dos controles, das resistências, encadeiam-se uns aos outros, segundo algumas estratégias de saber e poder.

Assim, nos cursos de formação de professores/as, esses temas devem ser estudados a fim de orientá-los/as sobre como fazer uma abordagem não legitimada apenas pelo discurso biológico e da heteronormatividade.

Muito do que se pode notar nas atitudes de meninos e meninas é formado também na escola, que tende a definir o que é certo e errado, o que vestir ou como agir; o corpo é definido pela sociedade, que nos impõe um estereótipo pelo que julga ser um corpo bonito, jovem e saudável, colaborando para a disseminação do 


\title{
Atos de Pesquisa em Educação - ISSN 1809-0354 \\ Blumenau, v. 12, n.3, p.783-806, set./dez. 2017 \\ DOI: http://dx.doi.org/10.7867/1809-0354.2017v12n3p783-806
}

bullying nas escolas, em função de características físicas, roupas, acessórios, adornos, modos de ser e estar no mundo.

No contexto escolar, também é evidente o preconceito quanto à raça e à etnia, uma vez que essas diferenças são colocadas como marcadores de inferioridade, gerando desigualdade e violência. Em geral, as pessoas tendem a rejeitar as diferenças, aceitando somente o que está dentro de um padrão de comportamento imposto socialmente. Para Silveira e Silveira (2012, p. 109):

\begin{abstract}
Quando duas pessoas se relacionam, a origem étnica é um dos fatores levado em conta em seu agir, diz respeito a sua postura diante do outro. Neste caso, a etnia soma-se a condição econômica (sua classe social), ao gênero, a aspectos geracionais, entre outros, como componentes de identificação social. A imagem que antecede o inter-conhecimento permitido pelo convívio social, é constituída a partir destas referências, as quais instituem um pré-conceito em relação ao outro.
\end{abstract}

Geralmente, quando estudamos os aspectos históricos, por exemplo, o/a negro/a, é lembrando no marco da abolição da escravatura, entretanto, questões sociais tão presentes em nossa cultura, como a capoeira, umbanda, comidas típicas, vestimentas etc., ganham pouco visibilidade. Muitas heranças da cultura africana prevalecem entre o povo brasileiro. Nunes (2012, p. 100) nos diz que "o movimento vivido e a necessidade de reconfigurar a diversidade étnica possibilitaram que povos de diferentes etnias fossem construindo práticas e fundando lugares". Ainda segundo a autora:

Em situações de cativeiro, trabalho forçado, homens e mulheres cantavam, denunciavam com melodias, sons e vozes que muitas vezes eram escutadas, compreendidas e depreendidas pelas expressões de seus corpos de modo a construir uma linguagem única, representativa da nova identidade que se construíra em terras brasileiras; identidade que não seria necessariamente de cativo, mas de homens e mulheres que obstinadamente iriam reverter tal condição. (NUNES, 2012, p. 100 -101).

Contudo, pouco se conhece sobre a cultura negra, e as questões de racismo ainda estão fortemente presentes no ambiente escolar, muitas vezes mascaradas como "brincadeiras". Cabe lembrar que a "brincadeira" é uma forma agressiva de disseminar o racismo e a intolerância, pois essa "brincadeira" em sua grande maioria nega ao/à agredido/a o direito de defesa. No contexto dessa discussão, é importante lembrar que passados todos esses anos da aprovação das leis 10.639/03 e 
 \\ Blumenau, v. 12, n.3, p.783-806, set./dez. 2017 \\ DOI: http://dx.doi.org/10.7867/1809-0354.2017v12n3p783-806}

11.645/08, que instituíram a inclusão no currículo oficial da rede de ensino a obrigatoriedade do estudo da História e Cultura Afro-brasileira e Indígena, ainda são pouco conhecidas e pouco implementadas em grande parte das instituições educativas públicas e privadas de todo o país.

Considerando as questões apresentadas até aqui, entendemos que os cursos de formação inicial de professores/as devem investir na formação de profissionais preparados/as para atuar na sociedade visando, dentre outras questões, a atender às necessidades de se discutir a diversidade existente na escola, que é uma das instâncias sociais diretamente ligada à formação das identidades dos sujeitos, tais como identidade de gênero, sexual, étnico-racial, dentre outras. Entendemos que a violência de gênero, a homofobia, a diversidade de gênero e sexual, a discriminação e o preconceito étnico-racial se configuram como demandas aos/às professores/as devido à importância da escola na constituição dos sujeitos e na construção de uma sociedade que respeite a diversidade, seja justa e democrática.

Assim, defendemos que a discussão sobre corpo, gênero, sexualidade, raça e etnia deve estar presente em todos os cursos de licenciatura, já que essas temáticas devem perpassar todas as disciplinas do currículo escolar, uma vez que não devem ser compreendidas como sendo de responsabilidade do/a professor/a de biologia ou de um/a profissional da área da saúde.

$\mathrm{Na}$ continuidade deste texto, descreveremos como a pesquisa foi desenvolvida metodologicamente a fim de atingir o objetivo investigativo.

\section{CAMINHOS METODOLÓGICOS}

Este estudo, de abordagem qualitativa, ancorou-se metodologicamente na análise documental, portanto, os documentos foram a nossa fonte de "coleta de dados". Segundo Oliveira (2007, p. 69), "na pesquisa documental as informações são retiradas de documentos, tais como, relatórios, jogos, materiais de divulgação, dentre outras fontes".

Para Triviños (1987, p. 111):

A "análise documental" é outro tipo de estudo descritivo que fornece ao investigador a possibilidade de reunir uma grande quantidade de informação 


\section{Atos de Pesquisa em Educação - ISSN 1809-0354 \\ Blumenau, v. 12, n.3, p.783-806, set./dez. 2017 \\ DOI: http://dx.doi.org/10.7867/1809-0354.2017v12n3p783-806}

sobre leis estaduais de educação, processos e condições escolares, planos de estudos, requisitos de ingresso, livros-textos etc.

Mai (1997) propõe uma síntese explicativa denominando a pesquisa documental com três etapas, sendo elas: o processo de análise de documento que é a descrição formal do documento; o processo de descrição do assunto em que se identifica, seleciona e extrai os conceitos do documento; o processo de análise do assunto, momento em que se faz a tradução de conceitos em verbetes do assunto.

A pesquisa de investigação sobre as questões de corpo, gênero, sexualidade, raça e etnia nos PPCs da UNIPAMPA foi realizada com uma análise nos Projetos Pedagógicos de Curso (PPCs) dos cursos de licenciaturas da Universidade Federal do Pampa.

O primeiro passo da pesquisa foi visitar o site da UNIPAMPA $^{2}$ e nos apropriarmos dos documentos que estavam disponíveis. Logo após, focamos no perfil do/a egresso/a a fim de verificarmos o perfil dos/as alunos/as dos cursos de licenciatura da instituição. A pesquisa nos documentos seguiu a ordem alfabética das cidades onde os cursos estão inseridos.

Num segundo momento, analisamos a composição curricular dos cursos a fim de observar a existência em seus currículos de uma disciplina específica que se trate das questões de corpo, gênero, sexualidade, raça e etnia.

Nos PPCs dos cursos que não apresentaram uma disciplina específica sobre o tema realizamos uma análise no ementário, para assim verificar se esses temas estão presentes em outras disciplinas e em que perspectiva teórica eles são apresentados.

\subsection{O PERFIL DO/A EGRESSO/A PRESENTE NOS PPC}

O perfil do/a egresso/a presente nos PPCs dos cursos de licenciatura referese ao perfil do/a profissional que se deseja formar. Os cursos em sua maioria seguem um mesmo padrão descritivo, ou seja, formar um/a profissional que planeje e organize as atividades com conhecimentos sólidos e consciente de suas

\footnotetext{
${ }^{2}$ http://novoportal.unipampa.edu.br/novoportal/
} 
 \\ Blumenau, v. 12, n.3, p.783-806, set./dez. 2017 \\ DOI: http://dx.doi.org/10.7867/1809-0354.2017v12n3p783-806}

atribuições com autonomia e pensamento crítico, visando a atender com excelência sua área de atuação.

O curso de Física do campus Bagé propõe a formação de um Físico "Educador, que seja um profissional com conhecimentos sólidos da física, capaz de abordar novos problemas, assim como os já existentes, além disso, realizar a transposição didática dos seus conhecimentos adquiridos" (PPC LICENCIATURA EM FÍSICA, 2014, p. 24). "Ser um profissional com cultura científica, e apto a utilizar recursos computacionais, ter ética e responsabilidade social na profissão e entender a ciência como conhecimento histórico, desenvolvido em diferentes contextos sóciopolíticos, culturais e econômicos" (PPC LICENCIATURA EM FÍSICA, 2014, p. 24).

Os cursos de Letras propõem a formação de um profissional que cumpra o seu papel social, desenvolvendo a pesquisa científica e o pensamento críticoreflexivo, assim como estar apto a trabalhar com a diversidade cultural brasileira, com consciência do papel do/a educador/a e da sua contribuição na difusão de valores e competências para a construção de uma sociedade democrática. Ainda trazem a necessidade de o/a egresso/a "estabelecer formas de interação a fim de promover a formação da identidade e suas diferenças, e promover a autonomia dos sujeitos que estão inseridos nas escolas" (PPC LICENCIATURA EM LETRAS, 2012, p.26). O perfil do/a egresso/a de Matemática traz a necessidade de formar um profissional capaz de dominar os conhecimentos matemáticos e ter consciência da importância do domínio desses conteúdos para o exercício da cidadania. "Trabalhar de forma colaborativa com os professores de outras áreas do saber assim como refletir sobre a própria prática" (PPC LICENCIATURA EM MATEMÁTICA, 2013, p. 97).

O/A egresso/a de Química deve, segundo seu PPC:

Compreender aspectos sociais inerentes a sua área de atuação e interagir com o desenvolvimento local, regional e/ou nacional. Ter uma formação generalista, ter preparação adequada à aplicação dos experimentos de química, assim como as competências necessárias para a atuação profissional (PPC LICENCIATURA EM QUÍMICA, 2012, p. 8).

O curso de Música compreende o perfil do/a egresso/a como este sendo capaz de ter uma visão crítica dos espaços em que a música é ensinada, assim como os espaços em que se aprende; e de reconhecer a existência da pluralidade 


\section{Atos de Pesquisa em Educação - ISSN 1809-0354 \\ Blumenau, v. 12, n.3, p.783-806, set./dez. 2017 \\ DOI: http://dx.doi.org/10.7867/1809-0354.2017v12n3p783-806}

cultural em que estamos inseridos/as, respeitando e promovendo o acesso à música de diferentes períodos, gêneros, culturas e etnias. "Exercitar o pensamento crítico e reflexivo sobre qual é o papel do educador na sociedade compreendendo suas funções e a complexidade em ensinar e aprender música" (PPC LICENCIATURA EM MÚSICA, 2014, p. 27).

O curso de Ciências Exatas de Caçapava do Sul propõe uma formação generalista e humana, em que os/as docentes formados/as sejam capazes de atuar no contexto educacional de forma autônoma, solidária, crítica e reflexiva.

Formar professores capazes atuar diante da atual conjuntura brasileira, ao contexto mundial e a sustentabilidade social, que construam saberes pautados na ética, e o respeito às individualidades entre outros elementos que constituem a sociedade (PPC LICENCIATURA EM CIÊNCIAS EXATAS, 2013, p. 27).

Em Dom Pedrito, o perfil do/a egresso/a do curso de Ciências da Natureza propõe que os/as egressos/as sejam capazes de atuar de maneira interdisciplinar nas áreas de biologia, física e química. Proporcionar aos/às discentes as possibilidades para uma interação mais efetiva com a comunidade, propiciando aos/às futuros/as docentes a participação em ações que viabilizem mudanças no cenário da educação regional. "Formar sujeitos conscientes das exigências éticas e da relevância pública e social dos conhecimentos, habilidades, atitudes e valores adquiridos na vida universitária" (PPC LICENCIATURA EM CIÊNCIAS DA NATUREZA, 2013, p. 15).

No curso de Educação do Campo, o perfil pretendido é de sujeitos conscientes das exigências éticas e da relevância pública e social dos conhecimentos, habilidades, atitudes e valores adquiridos na vida universitária. "Profissionais inseridos no contexto profissional de forma autônoma, crítica, reflexiva e solidária, comprometida com o desenvolvimento das comunidades rurais" (PPC LICENCIATURA EM EDUCAÇÃO DO CAMPO, 2013, p. 16).

O curso de Licenciatura em Matemática do campus Itaqui tem por objetivo formar profissionais com conhecimento no âmbito generalista e humanista, isto é, com autonomia intelectual, com consciência reflexiva, crítica e solidária passível de diagnosticar e amenizar os problemas educacionais contemporâneos locais, regionais e nacionais. "Profissionais com sólidos conhecimentos científicos e de 


\section{Atos de Pesquisa em Educação - ISSN 1809-0354 \\ Blumenau, v. 12, n.3, p.783-806, set./dez. 2017 \\ DOI: http://dx.doi.org/10.7867/1809-0354.2017v12n3p783-806}

conceitos matemáticos dentro do contexto da educação" (PPC LICENCIATURA EM MATEMÁTIA, 2011, p. 27).

No campus Jaguarão, o perfil do/a egresso/a do curso de Licenciatura em História requer a formação de profissionais generalistas, humanistas, uma formação de sujeitos conscientes da ética e da relevância pública social dos conhecimentos e habilidades adquiridos na universidade. "Formar cidadãos críticos e reflexivos, comprometidos com o desenvolvimento regional, nacional e sustentável" (PPC LICENCIATURA EM HISTÓRIA, 2013, p. 32).

No curso de Pedagogia, o perfil do/a egresso/a deve contemplar uma consistente formação teórica e prática, uma diversidade de conhecimentos que se articulam ao longo do curso. "O egresso do curso de Pedagogia deverá estar apto para atuar com ética e compromisso com vistas à construção de uma sociedade justa, equânime e igualitária" (PPC LICENCIATURA EM PEDAGOGIA, 2009, p. 16).

O campus São Borja, no que diz respeito às licenciaturas, possui apenas uma, a Licenciatura em Ciências Humanas, cujo objetivo é capacitar o/a egresso/a ao exercício do trabalho de docente em todas as suas dimensões.

Proporcionar ao egresso o pleno domínio da natureza do conhecimento humanístico e das práticas essenciais de sua produção e difusão. Então, o perfil dos egressos se norteia em formar um profissional crítico, comprometido com a ética e socialmente com as questões contemporâneas (PPC LICENCIATURA EM CIÊNCIAS HUMANAS, 2014, p. 32).

O curso de Licenciatura em Ciências Biológicas está localizado no campus São Gabriel e seu perfil de egresso/a é formar "professores conscientes das exigências éticas e da relevância social da profissão docente, capazes de atuar em contextos educacionais de forma autônoma, solidária, crítica e reflexiva" (PPC LICENCIATURA EM CIÊNCIAS BIOLÓGICAS, 2013, p. 13).

A cidade de Uruguaiana possui dois cursos de licenciatura, a de Ciências da Natureza que fundamenta o perfil do/a egresso/a em:

Um profissional capaz de criar desafios, problematizar e construir saberes, pautando-se pela ética e pelo respeito às individualidades, interagindo por meio das tecnologias de informação e de comunicação, valorizando as características regionais, as identidades culturais, a educação ambiental, as pessoas com necessidades especiais, dentre outros elementos que 


\section{Atos de Pesquisa em Educação - ISSN 1809-0354 \\ Blumenau, v. 12, n.3, p.783-806, set./dez. 2017 \\ DOI: http://dx.doi.org/10.7867/1809-0354.2017v12n3p783-806}

constituem a sociedade e o desenvolvimento do saber. (PPC LICENCIATURA EM CIÊNCIAS DA NATUREZA, 2014, p. 28).

E o curso de Educação Física que deseja formar educadores capazes de "planejar e intervir nas diferentes manifestações e modalidades culturais do movimento humano, tendo como pressuposto o reconhecimento das dimensões política, social e ética do seu fazer pedagógico". (PPC LICENCIATURA EM EDUCAÇÃO FÍSICA, 2012, p. 21).

Ao analisar o perfil do/a egresso/a dos cursos, percebemos que todos têm um objetivo em comum que é formar profissionais ativos, reflexivos e atuantes no meio educacional. Profissionais com ética, que respeitem os direitos individuais e as diferenças existentes no meio em que estão inseridos/as, docentes humanistas e comprometidos com a sociedade, para assim contribuir na formação dos sujeitos.

Diante dessas definições, cabe o questionamento de que estes profissionais também devem ser formados visando à compreensão de que as diferenças de corpo, gênero, raça e etnia estão presentes em todos os momentos da vida e devem ser respeitadas e discutidas no ambiente educacional. Acreditamos que estas discussões devem ser contempladas nos currículos dos cursos de formação de professores/as, pois assim irão contribuir significativamente em seu futuro profissional. Silva (2003, p. 150) nos diz que:

O currículo tem significados que vão muito além daqueles aos quais as teorias tradicionais nos confinaram. O currículo é lugar, espaço, território. $\mathrm{O}$ currículo é relação de poder. $\mathrm{O}$ currículo é trajetória, viagem, percurso. $\mathrm{O}$ currículo é autobiografia, nossa vida, curriculum vitae: no currículo se forma nossa identidade. O currículo é texto, discurso, documento. O currículo é documento de identidade.

Portanto, o currículo não é meramente uma listagem de conteúdos ou um documento que apresenta objetivos, disciplinas, conteúdos e temas a serem abordados. Mais do que isso, ele é processo de construção social, atravessado por relações de poder que fizeram e fazem com que tenhamos determinada definição de currículo, que fizeram e fazem com que o currículo inclua determinado tipo de conteúdo, determinada discussão (SILVA, 2003). Assim, entendemos que o currículo é o resultado de escolhas feitas pelos sujeitos com base nos saberes ou conhecimentos que consideram importantes. Nesse contexto, é importante 
DOI: http://dx.doi.org/10.7867/1809-0354.2017v12n3p783-806

questionar o "porquê" de determinadas escolhas, sobretudo, que sujeitos/profissionais da educação queremos formar com esse currículo, considerando o modelo de sociedade que se busca, pois, conforme lembra Silva (2003, p. 15) "um currículo busca precisamente modificar as pessoas que vão 'seguir' aquele currículo."

Considerando as questões apresentadas até aqui, na sequência analisaremos os currículos dos cursos de licenciatura da UNIPAMPA, tomando como base as ementas curriculares presentes nos PPCs desses cursos.

\section{UMA ANÁLISE SOBRE AS MATRIZES CURRICULARES DOS CURSOS DA UNIPAMPA}

Currículo e cultura caminham lado a lado; ele é uma maneira de reproduzir a cultura existente na sociedade, portanto, o currículo pode tanto reproduzir as relações de poder assim como causar grandes mudanças sociais. Segundo Silva (1996, p. 23):

O currículo é um dos locais privilegiados onde se entrecruzam saber e poder, representação e domínio, discurso e regulação. É também no currículo que se condensam relações de poder que são cruciais para o processo de formação de subjetividades sociais. Em suma, currículo, poder e identidades sociais estão mutuamente implicados. O currículo corporifica relações sociais.

Verificando as matrizes curriculares dos cursos de licenciatura da UNIPAMPA, percebemos a existência de alguns componentes curriculares que nos chamaram a atenção. O curso de Ciências da Natureza do campus Uruguaiana possui um componente curricular específico para trabalhar esses temas, que é o componente curricular "Corpo, gênero, sexualidade e relações étnico-raciais na educação" que busca discutir as questões de corpo, gênero, sexualidade, etnia e raça

[...] como construções históricas, culturais e sociais, bem como, as implicações das práticas sociais e de diferentes artefatos culturais na constituição dos sujeitos, o sexismo e homofobia no contexto escolar e em outras instâncias sociais, a violência sexual e de gênero e equidade no 


\section{Atos de Pesquisa em Educação - ISSN 1809-0354 \\ Blumenau, v. 12, n.3, p.783-806, set./dez. 2017 \\ DOI: http://dx.doi.org/10.7867/1809-0354.2017v12n3p783-806}

contexto atual. (PPC LICENCIATURA EM CIÊNCIAS DA NATUREZA, 2014, p. 28).

O curso de Ciências da Natureza de Dom Pedrito tem dois componentes curriculares que chamaram a atenção. Um deles é "Corpo Humano e saúde", porém ao analisarmos sua ementa verificamos que um de seus objetivos é conhecer e identificar estruturas, tecidos, órgãos e sistemas do corpo humano, de forma a estabelecer, futuramente, a comparação destas estruturas anatômicas com outros vertebrados. Portanto, o corpo humano é tratado apenas sob um viés biológico, e na questão da saúde não é vista a relação do "bem estar" psicológico que é tão importante para a qualidade de vida. Nessa direção, Souza (2007) nos diz que a educação tem tratado o corpo humano apenas como um fenômeno biológico, um organismo constituído de sistemas, órgãos, células e genes, assim, geralmente as características estudadas são puramente anatômicas, e os aspetos sociais, históricos e culturais deixam de ser abordados.

O outro componente curricular é a "Antropologia, multiculturalismo, ética e cidadania"; em sua ementa diz que o objetivo é conhecer a legislação vigente relacionada ao multiculturalismo, divulgando e produzindo conhecimentos, atitudes, posturas e valores que eduquem cidadãos para a diversidade. Visa à pluralidade étnico-racial, tornando-os capazes de interagir e de negociar objetivos comuns que garantam a todos respeito aos direitos legais e valorização de identidade na busca da consolidação da democracia brasileira. A partir dos dados não ficou claro como são trabalhadas essas identidades, como são construídas, e o fato de que ao longo da vida uma pessoa possa apresentar muitas identidades, que não são fixas, mas contraditórias, plurais e que são construídas culturalmente ao longo da vida.

No curso de História de Jaguarão, encontramos três componentes curriculares. O componente "História da África e da Cultura Afro-Brasileira" faz referência ao debate historiográfico, à África pré-colonial, ao processo de colonização e descolonização, ao tráfico negreiro e à cultura afro-brasileira. Acreditamos na importância que teria se fossem discutidas todas as heranças do povo africano, como a religião, a capoeira etc.

Cabe ressaltar que a Secretaria de Promoção da Igualdade Racial (Sepir), em 2009, elaborou em parceria com o MEC o Plano Nacional de Implementação das 


\section{Atos de Pesquisa em Educação - ISSN 1809-0354 \\ Blumenau, v. 12, n.3, p.783-806, set./dez. 2017 \\ DOI: http://dx.doi.org/10.7867/1809-0354.2017v12n3p783-806}

Diretrizes Curriculares Nacionais para a Educação das Ralações Étnico-Raciais e para o Ensino de História Afro-Brasileira e Africana.

O Plano tem como finalidade intrínseca a institucionalização da implementação da Educação das Relações Etnicorraciais, maximizando a atuação dos diferentes atores por meio da compreensão e do cumprimento das Leis 10639, de 2003 e 11645, de 2008, da Resolução CNE/CP 01, de 2004 e do Parecer CNE/ CP 03, de 2004. (PARECER CNE/CP 3/2004, p. 16).

Ainda:

Este plano não acrescenta nenhuma imposição às orientações contidas na legislação citada, antes "busca sistematizar essas orientações, focalizando competências e responsabilidades dos sistemas de ensino, instituições educacionais, níveis e modalidades". (PARECER CNE/CP 3/2004, p. 16).

Assim, fica clara a valorização e o reconhecimento das ações afirmativas no que diz respeito à educação para as relações étnico-raciais o Ensino de História Afro-Brasileira e Africana.

O componente "Direitos Humanos e Cidadania" têm como objetivo estudar o contexto histórico de criação dos direitos humanos e da cidadania no ocidente e sua trajetória no Brasil. Propõe o estudo da luta de diferentes grupos sociais contra o processo de exclusão social produzido pelo modo de produção capitalista.

"História e Cultura Indígena", também presente no curso de História, tem a intenção de fazer uma discussão sobre problemas, abordagens e perspectivas teórico-metodológicas inerentes às pesquisas sobre as sociedades indígenas em seus múltiplos aspectos históricos e culturais, assim como as políticas indígenas no Brasil. Na Lei de Diretrizes e Bases (LDB), criada em 1996, os artigos 78 e 79 são dedicados ao ensino voltado para os índios, e estipulam que a União deve desenvolver programas de ensino e pesquisa a fim de oferecer uma educação bilíngue e intelectual aos povos indígenas. O objetivo é recuperar suas memórias históricas, a reafirmação de suas identidades étnico-raciais e a valorização de suas línguas e conhecimentos, no caso do ensino de línguas, o ensino bilíngue, sendo ofertado pelo Estado, valorizando sua língua materna.

No curso de Educação Física do campus Uruguaiana, o componente curricular de "Antropologia do Corpo" estuda racionalidades e experiências acerca 
 \\ Blumenau, v. 12, n.3, p.783-806, set./dez. 2017 \\ DOI: http://dx.doi.org/10.7867/1809-0354.2017v12n3p783-806}

do corpo na cultura contemporânea e tem como objetivo abordar as representações socioculturais sobre a dimensão do corpo e da saúde, também visa a conhecer as teorias antropológicas que abordam o corpo, a saúde e suas relações com a cultura.

Dos sete componentes curriculares analisados nas matrizes curriculares dos cursos de licenciatura da UNIPAMPA, apenas o componente de "Corpo Humano e Saúde" do campus Dom Pedrito não contempla as discussões acerca das implicações sociais existentes atualmente, tratando o corpo apenas a partir de um viés biológico.

Frente à realidade apresentada nos PPCs, cabe refletir sobre a importância da inclusão dessas temáticas nos cursos de formação de professores/as, pois assim terão subsídios para realizar discussões sempre que for pertinente sobre as questões de corpo, gênero, sexualidade, raça e etnia no ambiente escolar.

A escola está, assim como outras instâncias da sociedade, diretamente envolvida na formação dos sujeitos e de suas identidades; entendemos, então, que os/as professores/as compartilham diretamente suas ideias e aprendizagens com os/as alunos/as. Portanto, os saberes construídos ao longo de sua formação devem contemplar esses conhecimentos a fim de fugir do discurso hegemônico presente na escola. Refletir essas temáticas nos cursos de licenciatura é uma maneira de oportunizar uma formação pautada na realidade e priorizar a construção de sujeitos autônomos, que saibam agir com respeito diante das diversidades.

Reforçamos nosso entendimento de que as questões de corpo, gênero, sexualidade, raça e etnia estão presentes em todos os momentos da vida, principalmente nas interações que existem no ambiente escolar; e contemplar essas discussões implica em uma valorização da diversidade nela existente.

\section{CONSIDERAÇÕES FINAIS}

Pensar na formação de professores/as é pensar em que tipo de sujeitos está sendo formado, bem como no seu papel na construção de aprendizagens que respeitem a diversidade existente no meio escolar.

A importância da formação a respeito das questões as quais envolvem sexualidade, gênero, raça e etnia são reconhecidas pelo MEC, que, desde o ano de 
 \\ Blumenau, v. 12, n.3, p.783-806, set./dez. 2017 \\ DOI: http://dx.doi.org/10.7867/1809-0354.2017v12n3p783-806}

2004 por meio da Secadi, tem incentivado o desenvolvimento de projetos buscando contribuir para o desenvolvimento inclusivo dos sistemas de ensino, voltado à valorização das diferenças e da diversidade, à promoção da educação inclusiva, dos direitos humanos e da sustentabilidade socioambiental. Visando à efetivação de políticas públicas transversais e intersetoriais, vem desenvolvendo diversos cursos de formação de professores a fim de auxiliar a formação de gestores e educadores, para assim transformar os sistemas educacionais em sistemas educacionais inclusivos (BRASIL, 2007).

Essa formação é direcionada para os/as profissionais da educação, mas também tem se dirigido à formação inicial. Contudo, mesmo contando com os investimentos do MEC, defendemos a importância de inserir essas temáticas nos currículos das licenciaturas como forma de investir na formação desses/as profissionais desde o curso de licenciatura. Deve-se prezar por uma formação que contemple essas temáticas visando à construção histórica, social e cultural, para que assim tais profissionais já entrem no mercado de trabalho conscientes do tipo de abordagem a ser feita em relação às questões de corpo, gênero, sexualidade, raça e etnia.

Assim, acreditamos que esses temas se fazem necessários nos cursos de licenciatura, o que pode ocorrer com a inserção de um componente curricular específico ou de modo transversal no currículo do curso de licenciatura. Contudo, destacamos que a discussão não pode ser relegada apenas às Disciplinas Complementares de Graduação, pois as mesmas são opcionais. Se na escola transitam hoje alunos/as de diferentes identidades oriundos/as de diferentes contextos, precisamos formar professores/as aptos para trabalhar na perspectiva da diversidade social e cultural, assim, estaremos contribuindo para a construção de uma sociedade justa e igualitária. Para formar sujeitos aptos a atender essas demandas, faz-se necessário uma reestruturação nos PPCs, visto que estes documentos não são estáticos e sim (re) construídos a fim de atender as necessidades atuais.

\section{CARLA ADRIANE MARCELINO DAMACENA}


Atos de Pesquisa em Educação - ISSN 1809-0354

Blumenau, v. 12, n.3, p.783-806, set./dez. 2017

DOI: http://dx.doi.org/10.7867/1809-0354.2017v12n3p783-806

Licenciada em Ciências da Natureza pela Universidade Federal do Pampa. Estudante da Pós-Graduação em Coordenação Pedagógica da Faculdade Fael. Professora das séries iniciais do Ensino Fundamental.

\section{EMERSON DE LIMA SOARES}

Licenciado em Ciências da Natureza pela Universidade Federal do Pampa. Estudante do curso de Mestrado em Educação em Ciências: Química da Vida e Saúde da Universidade Federal de Santa Maria.

\section{FABIANE FERREIRA DA SILVA}

Doutora em Educação em Ciências pela Universidade Federal do Rio Grande (2012), Mestra em Educação em Ciências pela Universidade Federal do Rio Grande do Sul (2007). Professora Adjunta da Universidade Federal do Pampa, Campus Uruguaiana.

\section{REFERÊNCIAS}

BRASIL. Lei no 10.639, de 9 de janeiro de 2003. Altera a Lei no 9.394, de 20 de dezembro de 1996, que estabelece as diretrizes e bases da educação nacional, para incluir no currículo oficial da Rede de Ensino a obrigatoriedade da temática "História e Cultura Afro-Brasileira", e dá outras providências. Diário Oficial da União, Brasília, DF, 2003.

BRASIL. Ministério da Educação. Secretaria de Educação Continuada, Alfabetização e Diversidade (SECAD). Caderno de Gênero e Diversidade Sexual na Escola: reconhecer diferenças e superar preconceitos. Brasília, 2007.

BRASIL. Lei $n^{\circ} 11.645$, de 10de março de 2008. Altera a Lei 10.639, de 9 de janeiro de 2003, que estabelece as diretrizes e bases da educação nacional, para incluir no currículo oficial da Rede de Ensino a obrigatoriedade da temática "História e Cultura Afro-Brasileira e Indígena" e de outras providências. Diário Oficial da União, Brasília, DF, 2008.

BRASIL. Ministério da Educação. Conselho Nacional de Educação. Resolução $N^{\circ} 2$, $D E 1^{\circ} D E$ JULHO DE 2015: Define as Diretrizes Curriculares Nacionais para a formação inicial em nível superior (cursos de licenciatura, cursos de formação pedagógica para graduados e cursos de segunda licenciatura) e para a formação continuada. Brasília, 2015. Disponível em:

<http://portal.mec.gov.br/index.php?option=com_docman\&view=download\&alias=17 719-res-cne-cp-002-03072015\&Itemid=30192>. Acesso em: 12 jul. 2017.

BRITZMAN, D. Curiosidade, sexualidade e currículo. In. LOURO, G. L. (Org.). O corpo educado: pedagogias da sexualidade. Belo Horizonte: Autêntica, 2001. p. 83111. 


\section{Atos de Pesquisa em Educação - ISSN 1809-0354 \\ Blumenau, v. 12, n.3, p.783-806, set./dez. 2017 \\ DOI: http://dx.doi.org/10.7867/1809-0354.2017v12n3p783-806}

CARVALHO, M. E. P. de. Gênero é um conceito complexo e de difícil sensocomunização: Considerações a partir de uma experiência de formação docente. Instrumento - Revista de Estudo Pesquisa em Educação. Juiz de Fora, v. 12, n. 2, p. 75-87, jul./dez. 2010. Disponível em: < file:///C:/Users/Fabiane\%20Ferreira/Downloads/937-2886-1-PB.pdf>. Acesso em: 07 dez. 2017.

FIGUEIRÓ, M. N. D. Formação de Educadores sexuais: adiar não é mais possível. Campinas, SP: Mercado de Letras, Londrina, PR: Eduel, 2006.

FOUCAULT, M. Microfísica do poder. Rio de Janeiro: Graal, 1993.

FOSTER, D. W. Consideraciones sobre el estudio de la heteronormatividade em la literatura latinoamericana. Letras: literatura e autoritarismo, Santa Maria, n. 22, p. 4953, jan./jun. 2001. Disponível em:

<file:///C:/Users/Fabiane\%20Ferreira/Downloads/11823-51569-1-SM.pdf.> Acesso em: 07 dez. 2017

GOELLNER, S. V. A produção cultural do corpo. In: LOURO, G. L; NECKEL, J. F.; GOELLNER, S. V. (Orgs.). Corpo, gênero e sexualidade: um debate contemporâneo na educação. Rio de Janeiro: Vozes, 2003. p. 28-40.

LOURO, G. L. Segredos e mentiras do currículo: sexualidade e gênero nas práticas escolares. In: SILVA, L. H. A escola cidadã no contexto da globalização. Petrópolis: Vozes, 1998. p. 33-47.

LOURO, Guacira L. Pedagogias da sexualidade. In: LOURO, Guacira L. (Org.). O corpo educado: pedagogias da sexualidade. Belo Horizonte: Autêntica, 2001. p.7-35.

MAI, J. E. The concept of subject: on problems in indexing. In: Knowledge Organization for Information Retrieval. Proceedings of the 6th International Study Conference on Classification Research, 6, p. 60-67, 1997. Disponível em: <http://jenserikmai.info/Papers/1997_TheConceptOfSubjectOnProblemsInIndexing.p df>. Acesso em: 12 jan. 2015.

MEYER, D. E. Gênero e educação: Teoria e política. In: LOURO, G. L.; FELIPE, J., GOELLNER, S. V. (Orgs.). Corpo, gênero e sexualidade: um debate contemporâneo na educação. Petrópolis, RJ: Vozes, 2003. p. 9-27.

NUNES, G. H. L. Educação das relações étnico-raciais na escola. In: SILVA, F. F. da; FREITAS, D. P. S. de. (Orgs.). II Seminário Corpos, Gêneros, Sexualidades e Relações Étnico-Raciais na Educação. [recurso eletrônico] Uruguaiana, RS:

UNIPAMPA, 2012. P. 96-106. Disponível em:

$<$ http://porteiras.r.unipampa.edu.br/portais/sisbi/files/2013/07/Corpos-2012.pdf.> Acesso em: 07 dez. 2017 


\section{Atos de Pesquisa em Educação - ISSN 1809-0354 \\ Blumenau, v. 12, n.3, p.783-806, set./dez. 2017 \\ DOI: http://dx.doi.org/10.7867/1809-0354.2017v12n3p783-806}

OLIVEIRA, M. M. Como fazer pesquisa qualitativa. Petrópolis: Vozes, 2007.

PARECER CNE/CP 3/2004, de 10/03/2004: Diretrizes Curriculares Nacionais para a Educação das Relações Étnico-raciais e para o Ensino de História e Cultura Afrobrasileira e Africana. Disponível em:

<file:///C:/Users/Emersom/Downloads/diretrizes_curriculares.pdf>. Acesso em: 04 jun. 2015.

QUADRADO, R. P. Corpos híbridos: problematizando as representações de corpos no currículo escolar. In: RIBEIRO, P. R. C. Corpos, gêneros e sexualidades: questões possíveis para o currículo escolar. 2. ed. Revisada e ampliada. Rio Grande: FURG, 2008. p. 32-38.

SILVA, F. F. da. Lições de sexualidade na escola. In: SILVA, F. F. da; MELLO, E. M. B. (Orgs). Corpos, gêneros, sexualidades e relações étnico-raciais na educação [recurso eletrônico]. Uruguaiana, RS: UNIPAMPA, 2011. P. 146-157. Disponível em: $<$ http://porteiras.r.unipampa.edu.br/portais/sisbi/files/2013/07/Corpos-2011.pdf.> Acesso em: 07 dez. 2017.

SILVA, T. T. da. Identidades terminais: as transformações na política da pedagogia e na pedagogia da política. Petrópolis: Vozes, 1996.

Documentos de identidade: uma introdução às teorias do currículo. Belo Horizonte: Autêntica, 2003.

SILVEIRA, M. Í. C. M., da; SILVEIRA, P. R. C. da. As relações étnico-raciais e a diversidade cultural: implicações para a educação. In: SILVA, F. F. da; FREITAS, D. P. S. de (Orgs.). II Seminário Corpos, Gêneros, Sexualidades e Relações ÉtnicoRaciais na Educação. Uruguaiana, RS: UNIPAMPA, 2012. P. 108-118. Disponível em: <http://porteiras.r.unipampa.edu.br/portais/sisbi/files/2013/07/Corpos-2012.pdf.> Acesso em: 07 dez. 2017

SOUZA, N. G. S. de. O corpo como uma construção biossocial: implicações no ensino de Ciências. In: RIBEIRO, P. R. C.; QUADRADO, R. P. (Orgs.). Corpos, gêneros e sexualidades: questões possíveis para o currículo escolar. Rio Grande, RS: Editora da FURG, 2007. p. 15-21.

TRIVIÑOS, A. N. S. Introdução à pesquisa em ciências sociais: a pesquisa qualitativa em educação. São Paulo: Atlas, 1987.

UNIPAMPA. UNIVERSIDADE FEDERAL DO PAMPA /CIÊNCIAS BIOLÓGICAS. Projeto Pedagógico do Curso de Ciências Biológicas, São Gabriel, 2013. Disponível em:

$<$ http://cursos.unipampa.edu.br/cursos/cienciasbiologicas/files/2013/05/PPC_Ci\%C 3\%AAnciasBiol\%C3\%B3gicas_Licenciatura_132.pdf.> Acesso em: 07 nov. 2014.

UNIPAMPA. UNIVERSIDADE FEDERAL DO PAMPA /CIEENCIAS DA NATUREZA. Projeto Pedagógico do Curso de Ciências da Natureza, Dom Pedrito, 2013. 


\section{Atos de Pesquisa em Educação - ISSN 1809-0354 \\ Blumenau, v. 12, n.3, p.783-806, set./dez. 2017 \\ DOI: http://dx.doi.org/10.7867/1809-0354.2017v12n3p783-806}

Disponível em:<

http://dspace.unipampa.edu.br:8080/xmlui/bitstream/handle/123456789/110/PPC_Ci \%C3\%AAncias\%20da\%20Natureza_Dom\%20Pedrito.pdf?sequence=1\&isAllowe $\bar{d}=y$ >. Acesso em: 12 jan. 2015.

UNIPAMPA. UNIVERSIDADE FEDERAL DO PAMPA / CIÊNCIAS DA NATUREZA. Projeto Pedagógico do Curso de Ciências da Natureza, Uruguaiana, 2014.

Disponível em:

$<$ http://cursos.unipampa.edu.br/cursos/cienciasdanatureza/files/2011/05/PPC-

Ci\%C3\%AAncias-Natureza.pdf.> Acesso em: 16 jan. 2015.

UNIPAMPA. UNIVERSIDADE FEDERAL DO PAMPA /CIÊNCIAS EXATAS. Projeto Pedagógico do Curso de Ciências Exatas, Caçapava do Sul, 2013. Disponível em: $<$ http://cursos.unipampa.edu.br/cursos/cienciasexatas/files/2013/05/ciencias-exatasppc-25-nov-2011_FINAL.pdf.> Acesso em: 05 set. 2014.

UNIPAMPA. UNIVERSIDADE FEDERAL DO PAMPA /CIENNCIAS HUMANAS. Projeto Pedagógico do Curso de Ciências Humanas, São Borja, 2014. Disponível em:

<http://cursos.unipampa.edu.br/cursos/cienciashumanas/files/2012/02/licenciaturaem-Ci\%C3\%AAncias-Humanas-04-10-201111.pdf>. Acesso em: 05 nov. 2014.

UNIPAMPA. UNIVERSIDADE FEDERAL DO PAMPA / EDUCAÇÃO DO CAMPO. Projeto Pedagógico do Curso de Educação do Campo, Dom Pedrito, 2013.

Disponível em: <http://cursos.unipampa.edu.br/cursos/lecampodp/files/2014/06/PPC-Educa\%C3\%A7\%C3\%A3o-no-Campo-maio2014-colorido.pdf>. Acesso em: 20 jan. 2015.

UNIPAMPA. UNIVERSIDADE FEDERAL DO PAMPA /EDUCAÇÃO FÍSICA. Projeto Pedagógico do Curso de Educação Física, Uruguaiana, 2012. Disponível em:

<http://dspace.unipampa.edu.br:8080/xmlui/bitstream/handle/123456789/144/PPC_E duca\%C3\%A7\%C3\%A30\%20F\%C3\%ADsica_Uruguaiana.pdf?sequence=1\&isAllow ed=y>. Acesso em: 11 nov. 2014.

UNIPAMPA. UNIVERSIDADE FEDERAL DO PAMPA /FÍSICA. Projeto Pedagógico do Curso de Física, Bagé, 2014. Disponível em:

<http://cursos.unipampa.edu.br/cursos/licenciaturaemfisica/files/2014/05/PPC_LF\%C 3\%8DSICA_VERS\%C3\%830_2014.pdf>. Acesso em: 05 dez. 2014.

UNIPAMPA. UNIVERSIDADE FEDERAL DO PAMPA /História. Projeto Pedagógico do Curso de História, Jaguarão, 2013. Disponível em:

<http://cursos.unipampa.edu.br/cursos/historia/files/2013/03/PPC_Histo\%C2\%B4riaLicenciatura-UNIPAMPAfinal-redux.pdf>. Acesso em: 07 nov. $20 \overline{14}$.

UNIPAMPA. UNIVERSIDADE FEDERAL DO PAMPA /LETRAS/LÍNGUAS ADICONAIS. Projeto Pedagógico do Curso de Letras - Línguas Adicionais Inglês e Espanhol e Respectivas Literaturas, Bagé, 2012. Disponível em:

<http://cursos.unipampa.edu.br/cursos/cursodeletraslinguasadicionais/files/2014/03/ 


\section{Atos de Pesquisa em Educação - ISSN 1809-0354 \\ Blumenau, v. 12, n.3, p.783-806, set./dez. 2017 \\ DOI: http://dx.doi.org/10.7867/1809-0354.2017v12n3p783-806}

PPC_Letras_L\%C3\%ADnguas_Adicionais \%C3\%BAltimavers\%C3\%A3o21032014 .pdf>. Acesso em: 07 nov. $201 \overline{4}$.

UNIPAMPA. UNIVERSIDADE FEDERAL DO PAMPA /LETRAS/PORTUGUÊS. Projeto Pedagógico do Curso de Letras - Letras - Português e Literaturas de Língua Portuguesa, Bagé, 2014. Disponível

em:<http://cursos.unipampa.edu.br/cursos/letrasportugueseliteraturas/files/2013/04/P PC-Letras-Portugu\%C3\%AAs-e-Literaturas-de-LP-aprovado-no-CONSUNI.pdf> Acesso em: 07 nov. 2014.

UNIPAMPA. UNIVERSIDADE FEDERAL DO PAMPA / Licenciatura em Letras Português e Espanhol. Projeto Pedagógico do Curso de Licenciatura em Letras Português e Espanhol, Jaguarão, 2010. Disponível em:

$<$ http://dspace.unipampa.edu.br:8080/xmlui/bitstream/handle/123456789/123/PPC_L etras_Port\%20Espanhol_Jaguar\%C3\%A3o.pdf?sequence=1\&isAllowed=y>. Acesso em: 05 dez. 2014.

UNIPAMPA. UNIVERSIDADE FEDERAL DO PAMPA /MATEMÁTICA. Projeto Pedagógico do Curso de Matemática, Bagé, 2013. Disponível em:

<http://dspace.unipampa.edu.br:8080/xmlui/bitstream/handle/123456789/89/PPC_M atem\%C3\%A1tica\%20Licenciatura.pdf?sequence=1\&isAllowed=y> Acesso em: $0 \overline{7}$ nov. 2014.

UNIPAMPA. UNIVERSIDADE FEDERAL DO PAMPA / MATEMÁTICA. Projeto Pedagógico do Curso de Matemática, Itaqui, 2011. Disponível em:

<http://cursos.unipampa.edu.br/cursos/licenciaturaemmatematicaitaqui/files/2014/05/ PPC-Matematica-2014-v2.pdf>. Acesso em: 05 dez. 2014.

UNIPAMPA. UNIVERSIDADE FEDERAL DO PAMPA /MÚSICA. Projeto Pedagógico do Curso de Música, Bagé, 2014. Disponível em:

$<$ http://cursos.unipampa.edu.br/cursos/licenciaturaemmusica/files/2014/11/PPC_CU RSO_DE_M\%C3\%9ASICA3.pdf>. Acesso em: 02 out. 2014.

UNIPAMPA. UNIVERSIDADE FEDERAL DO PAMPA /PEDAGOGIA. Projeto Pedagógico do Curso de Pedagogia, Jaguarão, 2009. Disponível em:

$<$ http://cursos.unipampa.edu.br/cursos/pedagogia/files/2011/05/PPC_-_2009__PROPLAN-PEDAGOGIA.pdf>. Acesso em: 07 nov. 2014.

UNIPAMPA. UNIVERSIDADE FEDERAL DO PAMPA /QUÍMICA. Projeto Pedagógico do Curso de Química, Bagé, 2012. Disponível em:

$<$ http://cursos.unipampa.edu.br/cursos/licenciaturaemquimica/files/2011/03/PPC_LQ\%C3\%9Altima-Vers\%C3\%A3o.pdf>. Acesso em: 11 set. 2014. 